\title{
2-Methoxyestradiol enhances radiosensitivity in radioresistant melanoma MDA-MB-435R cells by regulating glycolysis via HIF-1 $\alpha /$ PDK1 axis
}

\author{
HONG ZHAO ${ }^{1-3^{*}}$, HUANGANG JIANG ${ }^{2,3^{*}}$, ZHENG LI ${ }^{2,3}$, YAFEI ZHUANG ${ }^{1-3}$, YINYIN LIU $^{1-3}$, \\ SHULIANG ZHOU ${ }^{1-3}$, YOUDE XIAO ${ }^{1-3}$, CONGHUA XIE $^{2,3}$, FUXIANG ZHOU ${ }^{2,3}$ and YUNFENG ZHOU YH $^{2,3}$ \\ ${ }^{1}$ Hubei Key Laboratory of Tumor Biological Behaviors, Zhongnan Hospital of Wuhan University; \\ ${ }^{2}$ Department of Radiation and Medical Oncology, Zhongnan Hospital of Wuhan University; ${ }^{3}$ Hubei Cancer Clinical \\ Study Center, Zhongnan Hospital of Wuhan University, Wuchang, Wuhan, Hubei 430071, P.R. China
}

Received December 23, 2016; Accepted March 13, 2017

DOI: 10.3892/ijo.2017.3924

\begin{abstract}
HIF-1 $\alpha$ overexpression is associated with radioresistance of various cancers. A radioresistant human melanoma cell model MDA-MB-435R (435R) was established by us previously. Compared with the parental cells MDA-MB-435 (435S), an elevated level of HIF-1 $\alpha$ expression in 435R cells was demonstrated in our recent experiments. Therefore, in the current study, we sought to determine whether selective HIF-1 $\alpha$ inhibitors could radiosensitize the 435R cells to X-ray, and to identify the potential mechanisms. Our data demonstrated that inhibition of HIF-1 $\alpha$ with 2-methoxyestradiol (2-MeOE2) significantly enhanced radiosensitivity of 435R cells. 2-MeOE2 increased DNA damage and ratio of apoptosis cells induced by irradiation. Whereas, cell proliferation and the expression of pyruvate dehydrogenase kinase 1 (PDK1) were decreased after 2-MeOE2 treatment. The change of expression of GLUT1, LDHA and the cellular ATP level and extracellular lactate production indicates that 2-MeOE2 suppressed glycolytic state of $435 \mathrm{R}$ cells. In addition, the radioresistance, glycolytic state and cell proliferation of 435R cells were also decreased after inhibiting pyruvate dehydrogenase kinase 1 (PDK1) with dichloroacetate (DCA). DCA could also increase DNA damage and ratio of apoptotic cells induced by irradiation. These results also suggest that inhibition of HIF-1 $\alpha$ with
\end{abstract}

Correspondence to: Professor Fuxiang Zhou or Professor Yunfeng Zhou, Department of Radiation and Medical Oncology, Zhongnan Hospital of Wuhan University, 169 Donghu Road, Wuchang, Wuhan, Hubei 430071, P.R. China

E-mail: happyzhoufx@sina.com

E-mail: yfzhouwhu@163.com

*Contributed equally

Key words: melanoma, HIF-1 $\alpha$, glycolysis, radiosensitivity, 2-MeOE2, dichloroacetate, metabolism
2-MeOE2 sensitizes radioresistant melanoma cells $435 \mathrm{R}$ to $\mathrm{X}$-ray irradiation through targeting the glycolysis that is regulated by PDK1. Selective inhibitors of HIF-1 $\alpha$ and glycolysis are potential drugs to enhance radiosensitivity of melanoma cells.

\section{Introduction}

Hypoxia-inducible factor- $1 \alpha$ (HIF- $1 \alpha$ ) plays a crucial role in the adaptation of cancer cells to hypoxia by activating transcription of target genes that regulate several biological processes, including cell proliferation, glucose metabolism and $\mathrm{pH}$ regulation (1). Slominski et al found that HIF-1 $\alpha$ was upregulated in advanced malignant melanoma compared with melanocytic nevi or thin melanomas localized to the skin (1). High expression level of HIF-1 $\alpha$ is an independent predictor of poor prognosis after radiotherapy $(2,3)$. 2-Methoxyestradiol (2-MeOE2) is a special inhibitor that suppresses HIF-1 $\alpha$ protein levels and its transcriptional activity. It was shown to inhibit the expression of HIF-1 $\alpha$ in a dose-dependent manner in cancer cells by depolymerising microtubules and blocking HIF-1 $\alpha$ nuclear accumulation (4). Activation of glycolytic genes by HIF-1 $\alpha$ is considered to be a very important factor for metabolic adaptation to hypoxia, with increased conversion of glucose to pyruvate and subsequently to lactate (5). Many studies demonstrated that the expression and activity of glycolytic enzymes and the lactic acid concentration were reduced by inhibiting HIF-1 $\alpha(6,7)$.

Kim et al found that HIF-1 suppressed glucose metabolism through the tricarboxylic acid cycle (TCA) by directly transactivating the gene encoding pyruvate dehydrogenase kinase 1 (PDK1). PDK1 inactivated the TCA cycle enzyme and pyruvate dehydrogenase $(\mathrm{PDH})$, which converted pyruvate to acetyl-CoA, and rescued these cells from hypoxia-induced apoptosis (8). HIF-1 $\alpha$ causes an increase in pyruvate dehydrogenase kinase 1 (PDK1), which acts to limit the amount of pyruvate entering the citric acid cycle, leading to decreased mitochondrial oxygen consumption. PDK downregulates the activity of PDH-E1 $\alpha$, decreases the oxidation of pyruvate in mitochondria, and increases 
the conversion of pyruvate to lactate in the cytosol. Dichloroacetate (DCA), as an inhibitor of pyruvate dehydrogenase kinase (PDK), decreases the glycolysis state of cells by leading to the reactivation of pyruvate dehydrogenase (PDH) and shifts glucose metabolism from glycolysis to mitochondrial oxidation (9).

The reprogramming of metabolism, especially the glucose metabolism is one of the hallmarks of cancer (10). Cancer cells have generally higher level of glucose uptake and lactate secretion, regardless of oxygen content. This phenomenon is called 'aerobic glycolysis' or the 'Warburg effect' $(11,12)$. Metabolic studies supported the metabolic switch toward aerobic glycolysis in melanoma cells $(13,14)$. Recently, some studies revealed that elevated glycolysis of cancer cells will not only provide a growth advantage but also involves in resistance to chemotherapy and ionizing radiation resistance $(15,16)$. High glycolytic states of tumor cells are known to correlate strongly with radioresistance (17-21).

In our previous study, radiosensitive/radioresistant human melanoma cell model MDA-MB-435/MDA-MB-435R was established (22). An elevated level of HIF-1 $\alpha$ expression in radioresistant melonoma cells was also demonstrated in our recent experiments. Therefore, we aimed to investigated the effect of HIF-1 $\alpha$ on glycolysis and radioresistance in the 435R cells. Since PDK1 is a key regulator of glycolysis and it can be downregulated by inhibition of HIF-1 $\alpha$, DCA was used in the recent study to elucidate the possible underlying mechanisms of 2-MeOE2 radiosensiting to radioresistant melanoma cells, especially the HIF-1 $\alpha /$ PDK1-mediated glycolysis.

\section{Materials and methods}

Cells, cell culture and reagents. Human melanoma cell line MDA-MB-435S was purchased from the Cell Bank of Type Culture Collection of Chinese Academy of Sciences (Shanghai, China). Cell lines were cultured in DMEM growth media (Life Technologies, Carlsbad, CA, USA) which was supplemented with $10 \%$ fetal bovine serum (FBS, Life Technologies) and maintained at $37^{\circ} \mathrm{C}$ in a humidified atmosphere at $5 \% \mathrm{CO}_{2}$. DCA and 2-MeOE2 were purchased from Sigma-Aldrich (St. Louis, MO, USA).

$X$-ray irradiation. Radioresistant cell model of MDA-MB$435 \mathrm{~S}$ were established by irradiation with X-ray. All the cells were first grown to approximately $90 \%$ confluence then irradiated by a Simens Primus Accelerator at an average dose rate of $2 \mathrm{~Gy} /$ fraction, total dose was $60 \mathrm{~Gy}$.

Colony formation assay. The standard clonogenic assay was performed as previously described $(23,24)$. Cells were digested with trypsin enzyme at room temperature for 30-60 sec and then the clumped cells were pipetted. The single cell suspension was adjusted and seeded into typical 6-well plates. Then, cells were left to settle overnight, and exposed to irradiation at room temperature with the dose of $0,2,4,6,8$ and $10 \mathrm{~Gy}$, then incubated at $37^{\circ} \mathrm{C}, 5 \% \mathrm{CO}_{2}$ for 14 days. After fixation and staining, colonies of $>50$ cells were scored. Surviving rates were evaluated relative to $0 \mathrm{~Gy}$ radiation treated controls. A single-hit multi-target model was used to analyze the data (25). The survival curve of each group was plotted as the log of the survival fraction vs. the radiation dose using GraphPad Prism 5.0 software.

RNA extraction and quantitative reverse transcription PCR. Total RNA was isolated using TRIzol regent (Invitrogen) following the manufacturer's instructions. First-strand cDNA was obtained using the RevertAid ${ }^{\mathrm{TM}}$ First-Strand cDNA Synthesis kit (Fermentas International, Inc., Burlington, ON, Canada). For the quantitative analysis of HIF-1 $\alpha$ mRNA, the human $\beta$-actin gene was used as an internal control. Primer sequences were designed as follows: HIF- $1 \alpha$ sense, TGCAA CATGGAAGGTATTGC, and antisense, TTCACAAATCAG CACCAAGC; $\beta$-actin sense, TGCGTTACACCCTTTCT TGA, and antisense, CACCTTCACCGTTCCAGTTT. The Threshold cycle $(\mathrm{Ct})$ values were measured by SYBR-Green PCR Master mix (Takara, Shiga, Japan) with Mx3000P (Stratagene, La Jolla, CA, USA). The Mx 3000P analysis program was used to analyze the results.

Cellular ATP content and extracellular lactate level. Cells $\left(1 \times 10^{6} / \mathrm{ml}\right)$ were seeded into 6 -well plates. The extracellular lactate level was detected by Lactic acid assay kit (Jiancheng, Nanjing, China) following the manufacturer's instructions. The cellular ATP content was determined by measuring the luminescence with an ATP-dependent bioluminescence assay kit (Jiancheng). Briefly, the cells $\left(1 \times 10^{6} / \mathrm{ml}\right)$ were seeded into 6-well plates, lysed with lyolysis on ice, collected into $1.5 \mathrm{ml}$ tubes, and centrifuged for $5 \mathrm{~min}$ at $10,000 \mathrm{x} \mathrm{g}$; the Absorbance Microplate Reader was used to determine the OD of the supernatant (BioTek Instruments Inc., Winooski, VT, USA) at $630 \mathrm{~nm}$ (A630). The ATP content was calculated according to the formula provided by manufacturer's instructions. The above procedures were performed three times under the same condition.

Mitochondrial membrane potential and apoptosis analysis. The mitochondrial membrane potential was detected by the JC-1 kit (Beyotime Biotechnology, Haimen, China). Cell suspensions at $1 \times 10^{5} / \mathrm{ml}$ were grown on glass coverslips with/without 2-MeOE2 for $2 \mathrm{~h}$ before irradiation treatment. At 30 min after irradiation, the cells were incubated with DPBS with $1 \mu \mathrm{l} \mathrm{JC}-1$ reagent at $37^{\circ} \mathrm{C}$ for $15 \mathrm{~min}$. Then, cells were washed three times. The mitochondrial membrane potential was detected under the fluorescence microscope. The increase of green fluorescence suggests the decrease of the mitochondrial membrane potential.

For detection of apoptosis, 200,000 cells were seeded in a 6 -well plate, pre-incubated with/without 2-MeOE2 for $2 \mathrm{~h}$ before irradiation treatment. The cells were harvested $48 \mathrm{~h}$ after irradiation. The cells were re-suspended in $100 \mu \mathrm{l}$ staining buffer with $5 \mu \mathrm{l}$ Annexin V- FITC (BD Pharmingen, San Jose, CA, USA) and stained at room temperature for $15 \mathrm{~min}$ followed by a quick staining with $1 \mu \mathrm{g} / \mathrm{ml}$ propidium iodide (PI). The samples were analyzed on LSRII flow cytometer (Cytomics FC 500; Beckman Coulter, Fullerton, CA, USA), and the data were analyzed using Flow Jo software (FlowJo, Ashlan, OR, USA). Cells were stained with Annexin V-fluorescein isothiocyanate and PI and classified into 4 subpopulations as follows: viable cells (Annexin V and PI double-negative), apoptotic cells (Annexin V-positive), 
A

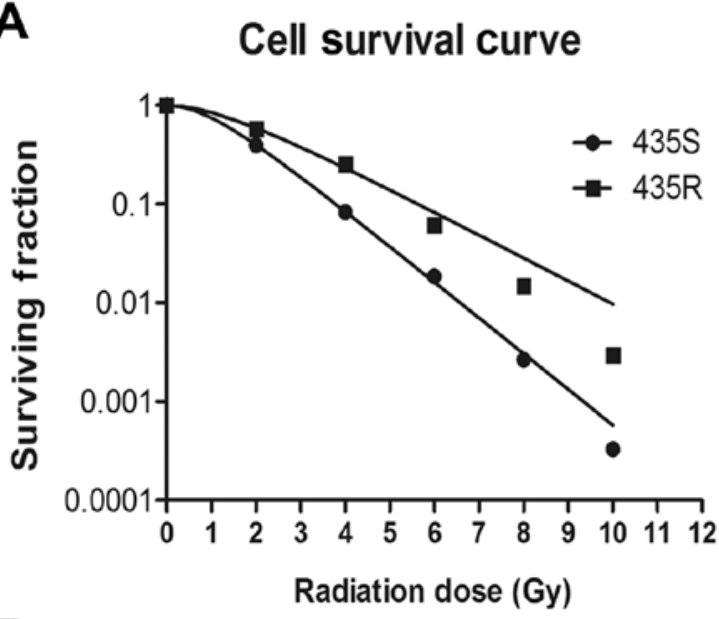

B

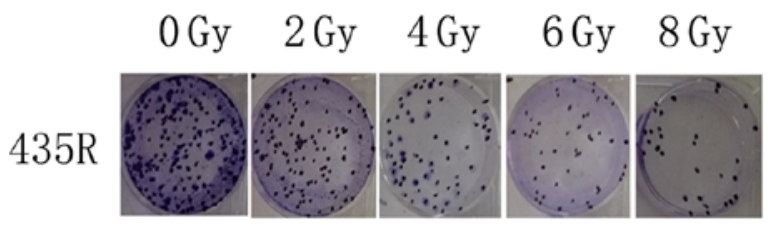

$435 \mathrm{~S}$

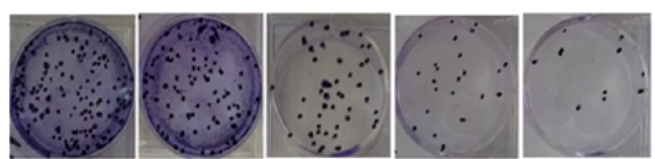

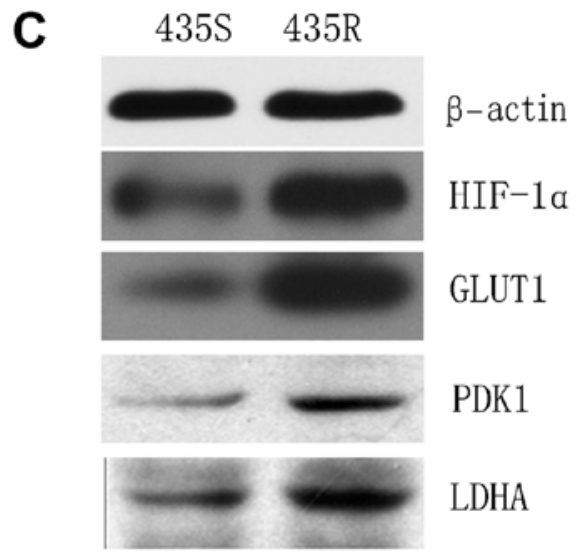

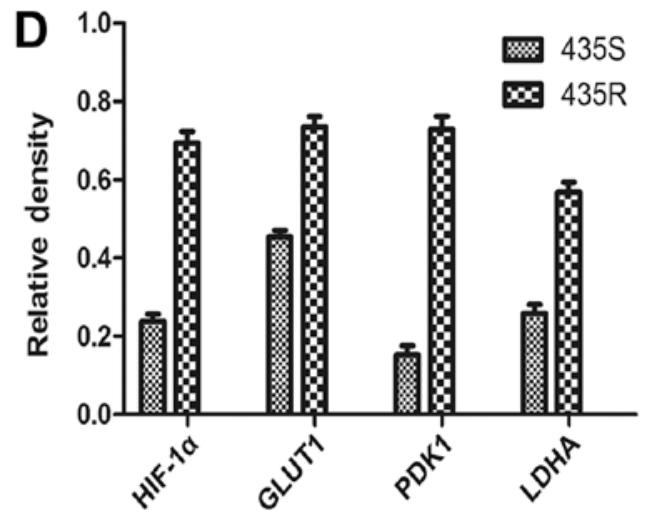

Figure 1. Expression of HIF-1 $\alpha$ and glycolysis-related proteins in radioresistant 435R and the parental 435S cells. (A) Radiosensitivity of 435R cells and 435S cells detected by colony formation assay. (B) Colony formation ability at the different irradiation doses of 435R cells and 435S cells. (C) Western blot analysis of HIF-1 $\alpha$, PDK1 and glycolysis-related proteins GLUT1, LDHA. (D) Relative density of HIF-1 $\alpha$, PDK1 and glycolysis-related proteins GLUT1, and LDHA normalized to their internal protein.

early dead cells (Annexin V and PI double-positive) and dead cells (PI-positive).

CCK-8 assay for cell proliferation. Cell proliferation was determined using a Cell Counting Kit-8 (CCK-8; Dojindo Kumamoto, Japan). Cells were seeded in 96-well plates, serum starved, and then treated with the experimental reagents as described (26). At the end of the incubation, CCK-8 solution was added and $3 \mathrm{~h}$ later, the absorbance at $450 \mathrm{~nm}\left(\mathrm{~A}_{450 \mathrm{~nm}}\right)$ was measured with a microplate reader (Sunrise). Cell proliferation rates were calculated and normalized with the OD value of the first day.

Immunofluorescence. The immunofluorescence of $\gamma$-H2AX foci was used to determine the residual DNA double-strand breaks (DSBs). Melanoma cells were grown on glass coverslips with/without 2-MeOE2 for $2 \mathrm{~h}$ before irradiation, $30 \mathrm{~min}$ after irradiation, cells were fixed in $4 \%$ paraformaldehyde for 15 min before staining overnight with rabbit anti- $\gamma-\mathrm{H} 2 \mathrm{AX}$ (ser139, Millipore Corp., Billerica, MA, USA) diluted in PBS 1:400. After staining for $60 \mathrm{~min}$ with goat anti-rabbit $\mathrm{Cy} 3$ (Millipore Corp.) diluted 1:100, the coverslips were mounted in Prolong Gold mounting medium containing DAPI (Life Technologies). Fluorescent images were obtained using Zeiss LSM710 confocal microscope (Leica Microsystems GmbH, Wetzlar, Germany) equipped with Plan-Apochromat X63/1.4
Oil DICII objective and analyzed using the ZEN2011 software and Adobe Photoshop CS5.

Protein isolation and western blot analysis. Briefly, $10 \times 10^{5}$ cells were seeded in $60 \mathrm{~mm}^{2}$ plates and cultured in the presence or absence of $5 \mu \mathrm{M} 2-\mathrm{MeOE} 2$ for $24 \mathrm{~h}$. Following treatment, cells were lysed on ice with lysis buffer (Cell Signaling Technology, Danvers, MA, USA) supplemented with $1 \mathrm{mM}$ phenylmethylsulfonyl fluoride (PMSF). Samples were centrifuged at $12,000 \mathrm{x}$ g for $10 \mathrm{~min}$ at $4^{\circ} \mathrm{C}$, and supernatant was aliquoted and stored at $-80^{\circ} \mathrm{C}$ for future use.

Total protein $(30 \mu \mathrm{g})$ was resolved in a $10 \%$ polyacrylamide gel using SDS-PAGE then transferred to a polyvinylidene difluoride (PVDF) membrane. Following transfer, membrane was blocked for $2 \mathrm{~h}$ at room temperature in 5\% non-fat dry milk diluted in $0.1 \%$ Tween-20 in TBS (TBST) followed by an overnight incubation in blocking solution with primary antibodies. After washing, membranes were incubated for $2 \mathrm{~h}$ at room temperature with the appropriate peroxidaseconjugated secondary antibody, washed, and subjected to chemiluminescent substrate (Luminata Forte; Millipore Corp.). Membranes were imaged using the ChemiDoc XRS+ system (Bio-Rad, Hercules, CA, USA) and densitometry was performed using Image Lab software (Bio-Rad). Every target protein of our experiment was calculated by gray scanning using ImageJ (free software from NIH website), the relative 


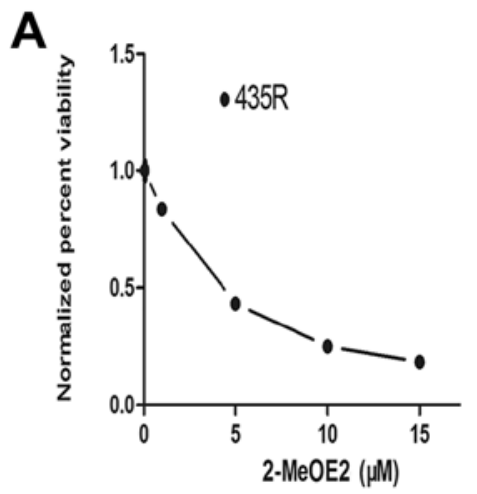

C

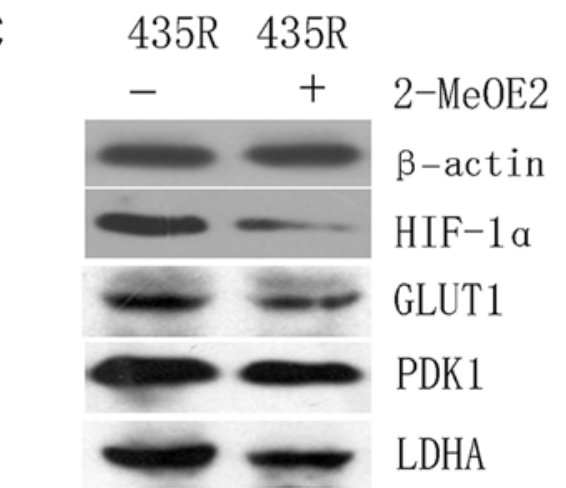

D

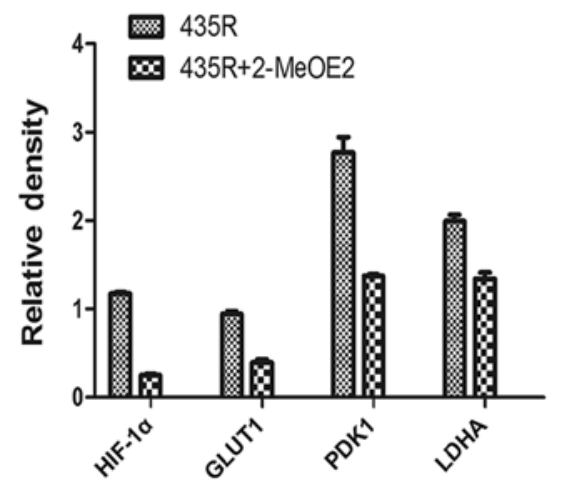

B

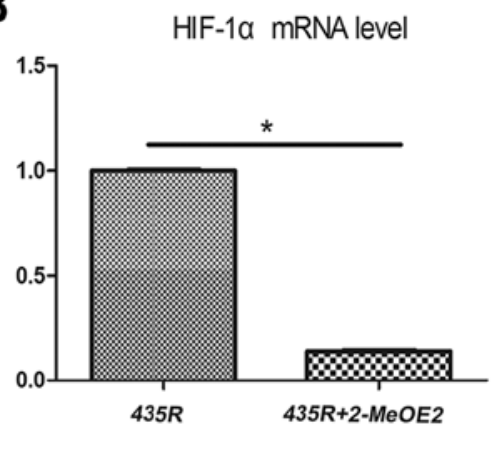

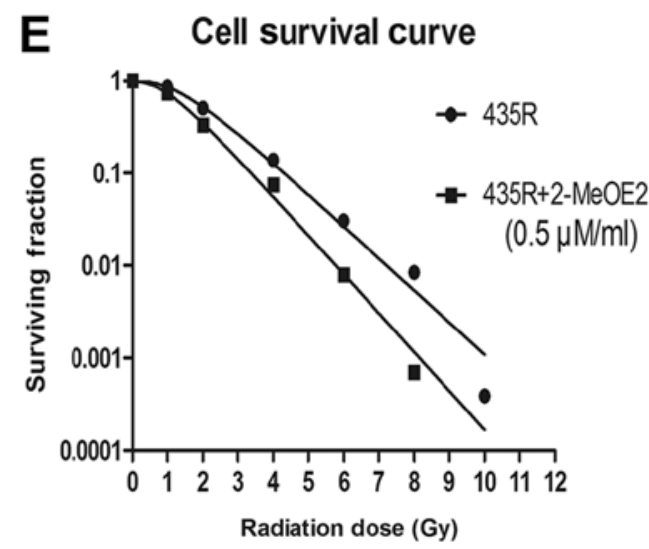

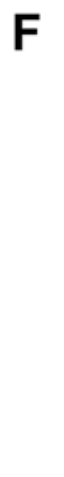

$435 \mathrm{R}$

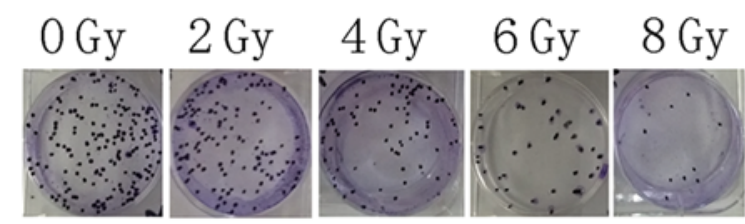

$435 \mathrm{R}^{+}$

2-MeOE2
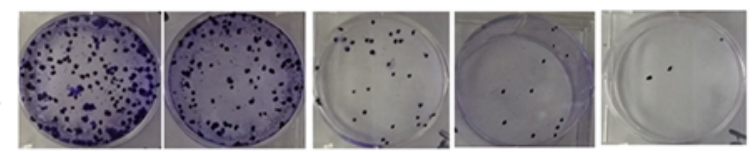

G Extracellular lactate content

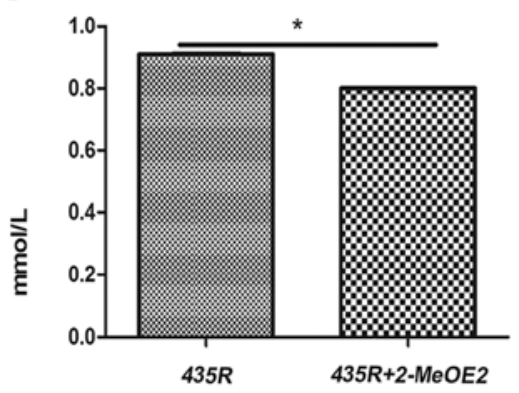

H Cellular ATP level

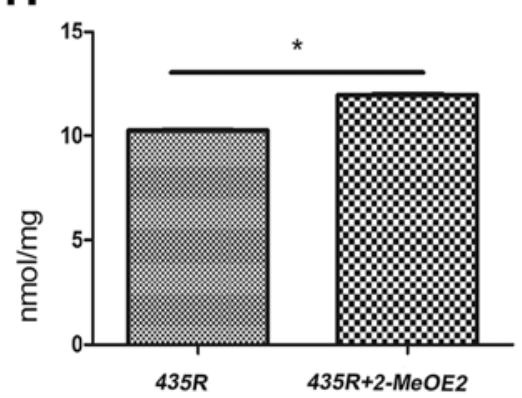

Figure 2. 2-MeOE2 decreases the radioresistance, PDK1 and glycolytic state of $435 \mathrm{R}$ cells. (A) The median $\mathrm{IC}_{50}$ of 2-MeOE2 for $435 \mathrm{R}$ cells. (B) The expression of HIF-1 $\alpha$ at mRNA level in 435R cells with/without 2-MeOE2, $\mathrm{P}<0.0001$. (C) The expression of HIF-1 $\alpha$, PDK1 and glycolysis-related proteins GLUT1, LDHA in 435R cells with/without 2-MeOE2. (D) Relative density of HIF-1 $\alpha$, PDK1 and glycolysis-related proteins GLUT1, LDHA that normalized to its internal protein. (E) The change of radiosensitivity of $435 \mathrm{R}$ cells with 2-MeOE2 detected by colony formation assay. (F) Colony formation ability at the different irradiation doses of 435R cells with/without 2-MeOE2. (G) Extracellular lactate content in 435R cells with/without 2-MeOE2, "P<0.0001. (H) Cellular ATP level in 435R cells with/without 2-MeOE2, $\mathrm{P}=0.0125$.

density of target proteins were normalized to its marker internal protein. Primary antibodies used included rabbit anti-HIF1- $\alpha, \beta$-actin, GLUT1, LDHA, PDK1. The quantification of band density was performed using ImageJ software.

Statistical analyses. All the experiments were repeated at least 3 times. Data are presented as the means \pm standard deviation (SD). Statistical analyses were performed using two-tailed Student's t-test (specified in the figure legend when paired analysis was used) and one way ANOVA using SPSS 19.0 and GraphPad Prism 5.0 software. The threshold for statistical significance was defined as $\mathrm{P} \leq 0.05$.

\section{Results}

HIF-1 $\alpha$ and glycolysis-related proteins were highly expressed in radioresistant melanoma cells. In this study, we used a radioresistant cell model of melanoma cells to investigate radioresistance of melanoma cells more accurately. Radioresistant cell model MDA-MB-435R (435R) was established from melanoma cell line MDA-MB-435 (435S) through continuous X-ray radiation (22). The results of colony formation assay show that 435R cells displayed stronger radioresistance compared with its parental $435 \mathrm{~S}$ cells (Fig. 1A and B), and demonstrate that we established the radioresistant cell model successfully. 
A

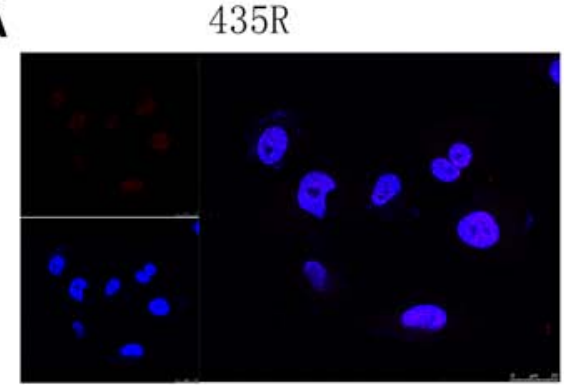

B

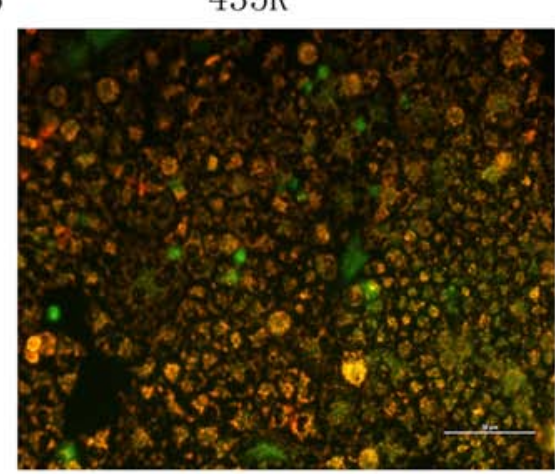

435R+6 Gy

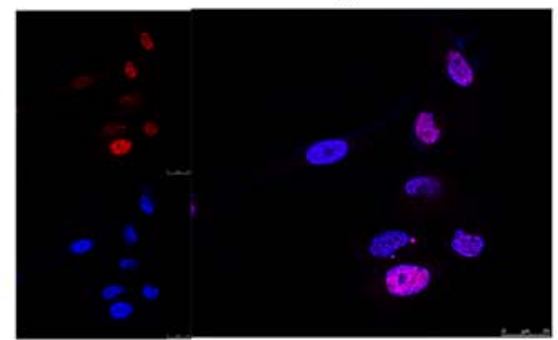

435R+6 Gy
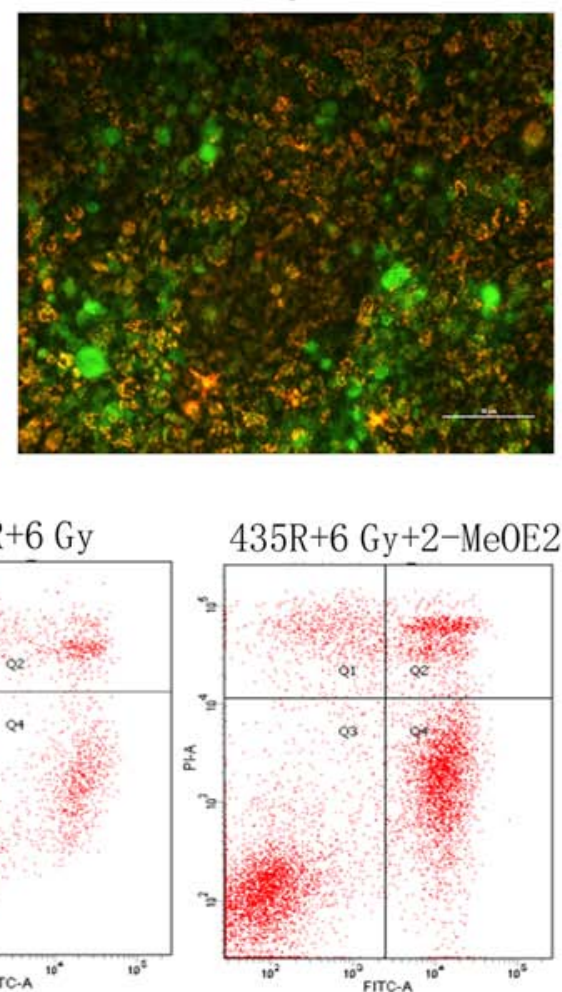

$435 \mathrm{R}+6 \mathrm{~Gy}+2-\mathrm{Me} 0 \mathrm{E} 2$

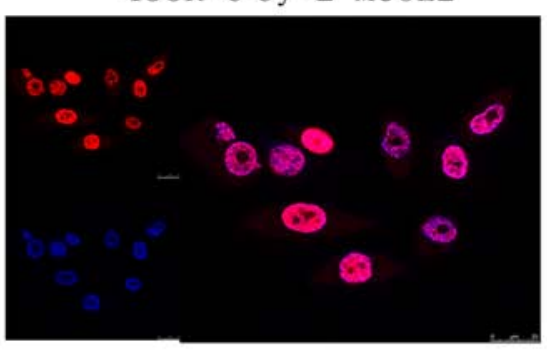

$435 \mathrm{R}+6 \mathrm{~Gy}+2-\mathrm{Me} 0 \mathrm{E} 2$

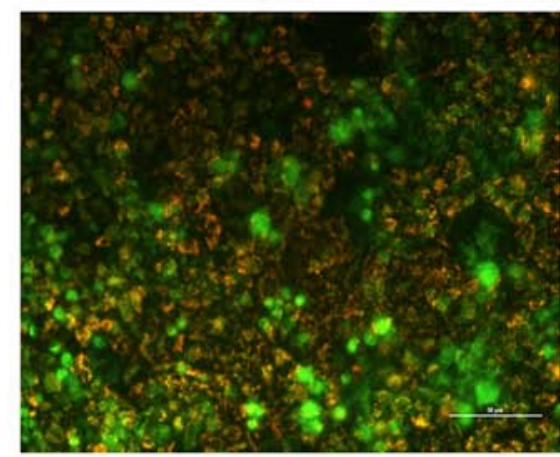

D Total apoptosis

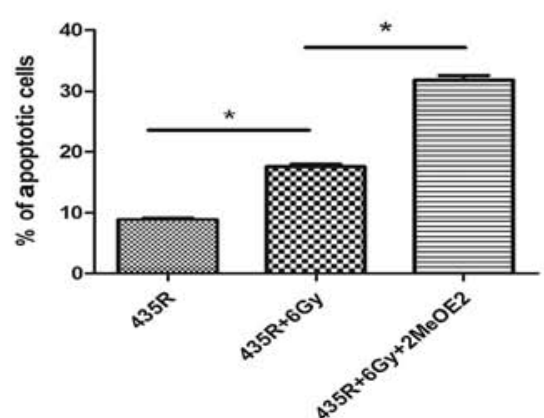

Figure 3. 2-MeOE2 increases DNA damage and apoptosis of 435R cells after irradiation. (A) $\gamma$-H2AX foci in combination treatment with 2-MeOE2 and RT or $\mathrm{RT}$ alone in 435R cells. Upper left corner of each image is the $\gamma$-H2AX foci with the red fluorescence in the nuclei. Lower left corner of each image is nuclei stained blue with DAPI. On the right side is the merged image of the left two images. (B) The change of mitochondrial membrane potential in combination treatment with 2-MeOE2 and RT or RT alone in 435R cells. The images demonstrate depolarization of mitochondrial membrane potential indicated by decrease of the red fluorescence combined with increase of the green fluorescence. (C) Apoptosis analyzed by flow cytometry in combination treatment with $2-\mathrm{MeOE} 2$ and RT or RT alone in 435R cells. (D) The percentage of apoptosis on 435R cells with different treatment, ${ }^{*} \mathrm{P}<0.001$.

Our data demonstrated that the expression of HIF-1 $\alpha$ in the 435R cells was higher than the parental cells 435S (Fig. 1C and D). Expression of the glycolysis-related proteins such as PDK1, GLUT1 and LDHA in the 435R cells were higher than the $435 \mathrm{~S}$ cells (Fig. 1C and D).

2-MeOE2 decreases radioresistance, PDK1 and glycolytic state of $435 R$ cells. The median IC50 of 2-MeOE2 was $4.3 \mu \mathrm{M}(48 \mathrm{~h})$ for $435 \mathrm{R}$ cells (Fig. $2 \mathrm{~A}$ ). Our data indicated that 2-MeOE2 at the concentration $\leq 0.5 \mu \mathrm{M}$ had no significant cytotoxic effect on $435 \mathrm{R}$ cells. Thus, we chose the 2-MeOE2 with $0.5 \mu \mathrm{M}$ (incubated with cells $6 \mathrm{~h}$ before irradiation) for our experiments. The expression of HIF-1 $\alpha$ at the mRNA and protein levels in the radioresistant cells were decreased after using the 2-MeOE2 (Fig. 2B and C). The results of colony formation assay show that survival fractions of $435 \mathrm{R}$ cells with 2-MeOE2 decreased significantly at different irradiation doses compared with the cells without 2-MeOE2 (Fig. 2E and F).

Decrease of PDK1 expression of 435R cells was detected after inhibiting HIF-1 $\alpha$ with 2-MeOE2. Extracellular lactate content and the expression of glycolysis-related proteins GLUT1 and LDHA of the 435R cells were decreased (Fig. 2C, D and G), and the cellular ATP level of 435R cells was increased after the 2-MeOE2 treatment (Fig. 2H). The results indicated that inhibition of HIF-1 $\alpha$ decreased the glycolytic states of $435 \mathrm{R}$ cells.

2-MeOE2 increases DNA damage and apoptosis of 435R cells after irradiation. $\mathrm{H} 2 \mathrm{AX}$ plays an essential role in the cellular response to DSBs of DNA induced by irradiation, the number of $\gamma-\mathrm{H} 2 \mathrm{AX}$ foci is proportional to the amount of DSBs. As 

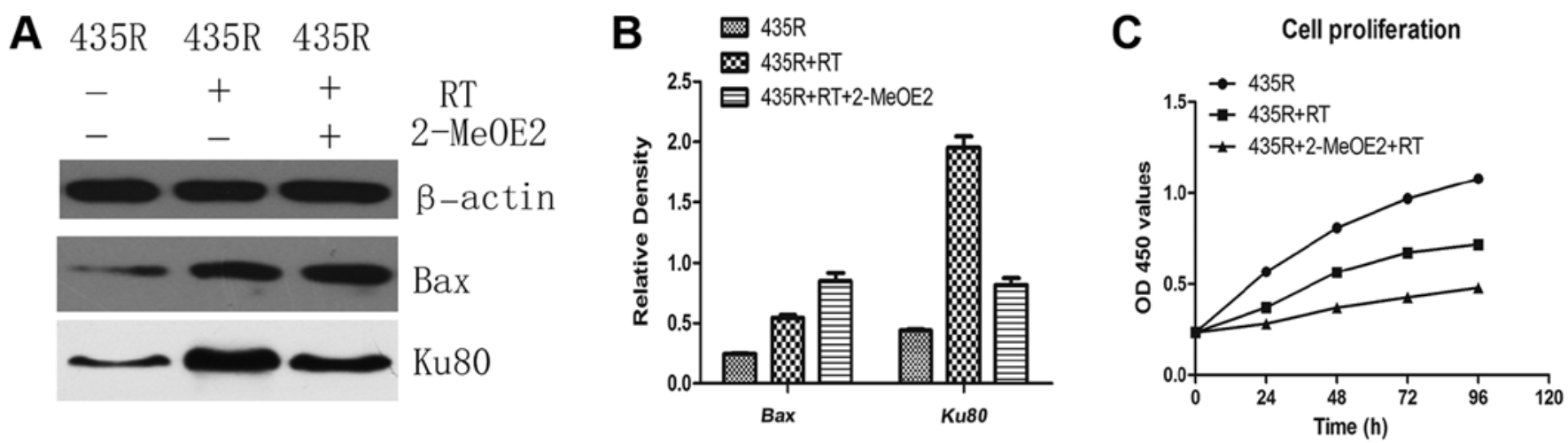

Figure 4. 2-MeOE2 decreases DNA damage repair and cell proliferation of 435R cells after irradiation. (A) Western blot analysis of Bax and Ku80 in 435R cells in combination treatment with 2-MeOE2 and RT or RT alone. (B) Relative density of Bax and Ku80 normalized to its internal protein. (C) Cell proliferation was detected using CCK-8 assays in 435R cells in combination treatment with 2-MeOE2 and RT or RT alone.

shown in Fig. 3A, The number of $\gamma$-H2AX foci in the 435R cells treated with 2-MeOE2 significantly increased compared with 435R without this after the same dose of irradiation.

It is well known that irradiation could cause DNA damage. If DNA damage can not been adequately repaired after irradiation, cells may progress towards apoptosis and/or necrosis. The decrease of mitochondrial membrane potential is an important factor in the early stage of apoptosis (27). The decrease of red fluorescence combined with the increase of green fluorescence suggested the loss of the mitochondrial membrane potential as shown in Fig. 3B. The mitochondrial membrane potential of $435 \mathrm{R}$ cells treated with $2-\mathrm{MeOE} 2$ decreased to a larger extent than the parental cells after irradiation (Fig. 3B). The results of flow cytometry showed that inhibition of HIF-1 $\alpha$ increased the apoptotic percentages of radioresistant cells after irradiation (Fig. 3C and D). The results of western blot analysis showed the expression of Bax was increased after irradiation treated with 2-MeOE2 (Fig. 4A and B).

2-MeOE2 decreases DNA damage repair and cell proliferation of $435 R$ cells after irradiation. The results of western blot analysis showed expression of DNA damage repair-related protein Ku80 in the 435R cells with 2-MeOE2 was decreased compared the 435R cells without treatment after irradiation (Fig. 4A and B). Cell proliferation was detected using CCK-8 assays. The result showed that inhibition of HIF- $1 \alpha$ with 2-MeOE2 can enhance suppression of cell proliferation of 435R cells induced by irradiation (Fig. 4C).

$D C A$ decreases radioresistance and glycolytic state of $435 R$ cells. In order to verify inhibition of HIF-1 $\alpha$ decrease the radioresistance of $435 \mathrm{R}$ cells via HIF-1 $\alpha /$ PDK 1 mediated glycolysis, radioresistance of $435 \mathrm{R}$ cells were detected after inhibiting glycolytic state with DCA. The result of colony formation assay show that survival fractions of 435R cells with DCA decreased significantly at different irradiation doses compared with those without DCA (Fig. 5A and B). The expression of glycolysis related proteins GLUT1, LDHA and the extracellular lactate content of the 435R cells were decreased (Fig. 5C-E), cellular ATP level of the 435R cells was increased after the DCA treatment (Fig. 5F).
DCA increases DNA damage and apoptosis of $435 R$ cells after irradiation. The number of $\gamma-\mathrm{H} 2 \mathrm{AX}$ foci in the $435 \mathrm{R}$ cells treated with DCA significantly increased compared with 435R without it after the same dose of irradiation (Fig. 6A). The mitochondrial membrane potential of $435 \mathrm{R}$ cells treated with DCA decreased to a larger extent than the $435 \mathrm{~S}$ cells after irradiation (Fig. 6B). The results of flow cytometry showed that DCA could increase the apoptotic percentage of radioresistant cells after irradiation (Fig. 6C and D). Furthermore, the expression of Bax was increased after irradiation when treated with DCA (Fig. 7A and B).

DCA decreases DNA damage repair and cell proliferation of $435 R$ cells after irradiation. The expression of Ku80 in the 435R with DCA was decreased compared to those without DCA after irradiation (Fig. 7A and B). The result of cell proliferation assays showed that inhibition of PDK1 with DCA can enhance suppression of cell proliferation of $435 \mathrm{R}$ cells induced by irradiation (Fig. 7C).

\section{Discussion}

The existence of radioresistance limits the efficacy of radiotherapy for melanoma. However, recent studies suggest that under certain clinical circumstances, radiotherapy may play a significant role in the treatment of melanoma (28-31). Improving the radiosensitivity of melanoma cells may allow the expanded use of radiotherapy for melanoma. The results of our study indicated that the level of HIF-1 $\alpha$ and glycolysis in the radioresistant cells were higher than its parental cells. Inhibition of HIF-1 $\alpha$ sensitizes radioresistant melanoma cells 435R to X-ray irradiation by targeting the energy metabolism regulated by glycolysis.

HIF-1 $\alpha$ is an important regulator in the cellular and systemic homeostatic responses to hypoxia by activation of gene transcription (32). HIF-1 $\alpha$ overexpression is associated with radioresistance of several tumors. Therefore, selective HIF-1 $\alpha$ inhibitors are promising targeted compounds for adjuvant radiosensitizing therapy. In our study, we inhibited the expression of HIF-1 $\alpha$ in the radioresistant melanoma cells $435 \mathrm{R}$ with the special chemical molecule 2-MeOE2. 2-MeOE2 as a special inhibitor of HIF-1 $\alpha$ was shown to inhibit the expression 

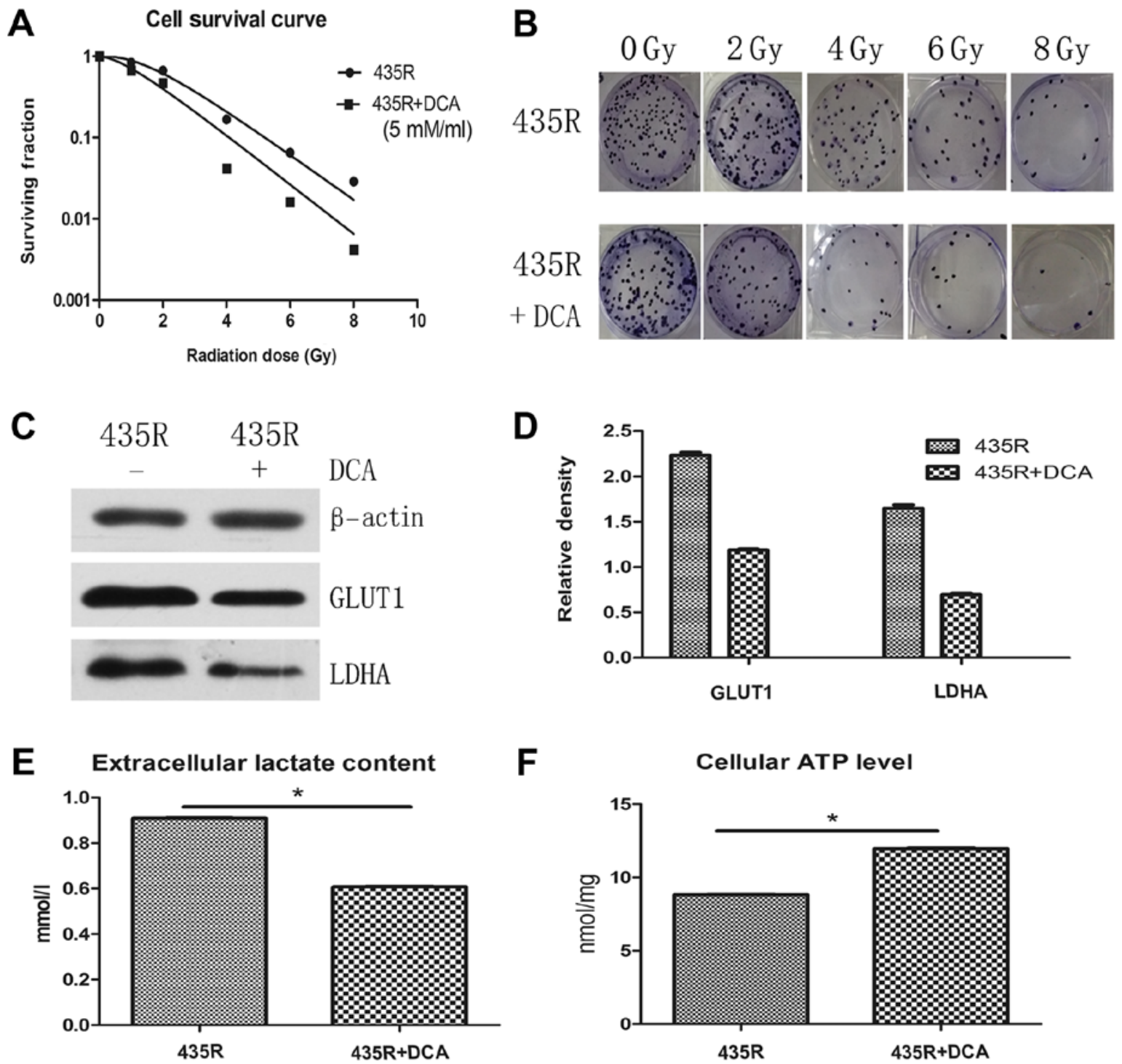

Figure 5. DCA decreases the radioresistance and glycolytic state of 435R cells. (A) The change of radiosensitivity of 435R cells with DCA detected by colony formation assay. (B) Colony formation ability at the different irradiation doses of 435R cells with/without DCA. (C) The expression of glycolysis-related proteins GLUT1, LDHA in 435R cells with/without DCA. (D) Relative density of GLUT1, LDHA that normalized to its internal protein. (E) Extracellular lactate content in 435R cells with/without DCA, ${ }^{*} \mathrm{P}<0.001$. (F) Cellular ATP level in 435R cells with/without DCA, ${ }^{*} \mathrm{P}<0.001$.

of HIF-1 $\alpha$ in a dose-dependent manner in cancer cells and blocking HIF-1 $\alpha$ nuclear accumulation by depolymerizing microtubules (4). When detected the expression of proteins in our study, use of $\beta$-tubulin was avoided as the internal reference to prevent the influence of change of level of microtubules. We also avoided use of GAPDH as the internal reference to prevent influence of the change of level of GAPDH caused by glycolytic activity. $2 \mathrm{MeOE}-2$ is a naturally occurring derivative of estradiol, which has been shown to be orally active, well-tolerated small molecule that possesses antitumor and anti-angiogenic activity (33). There are several completed Phase I/II clinical trials for the effectiveness of $2 \mathrm{MeOE}-2$ in various cancers (34-36).

Activation of glycolytic genes by HIF-1 $\alpha$ is considered to be a very important factor for metabolic adaptation to hypoxia, with increased conversion of glucose to pyruvate and subsequently to lactate. HIF-1 also suppressed glucose metabolism through the tricarboxylic acid cycle by directly transactivating PDK1. PDK1 is an important glucose metabolism enzyme for the Warburg effect, promotes the conversion of pyruvate to lactic acid and ATP in the presence of oxygen (aerobic glycolysis), generating the necessary amount of energy needed for rapid cellular proliferation (10). Lactate dehydrogenase A (LDHA) is an enzyme which plays a critical role in the glucose metabolism. Expression and post-transcriptional modification of LDHA are regulated by several known oncogenes and deacetylases, such as MYC and HIF-1 $\alpha$ (37-39). GIUT1 is a facilitative glucose transporter which belongs to the solutelinked carrier gene family SLC2, and the elevated expression of GLUT1 has been documented in most cancers (40). We have detected the indicators of glycolysis in the radioresistant cell model and the parental cells, and the results show that the expression of PDK1, LDHA and GLUT1 in the radioresistant cells were higher than its parental cells. In addition, extracellular lactate production in the radioresistant cells were also higher than the parental cells. These results show evidence that highly level of HIF-1 $\alpha$ and glycolysis has an important relationship with the radioresistance of melanoma cells. 
A

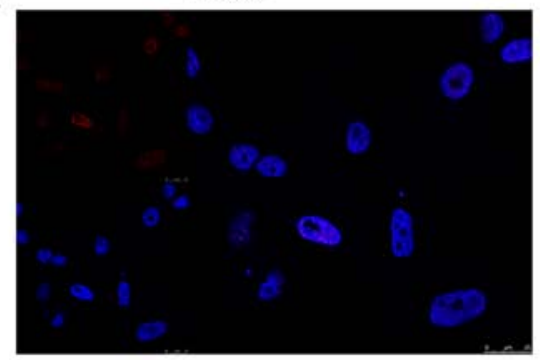

B

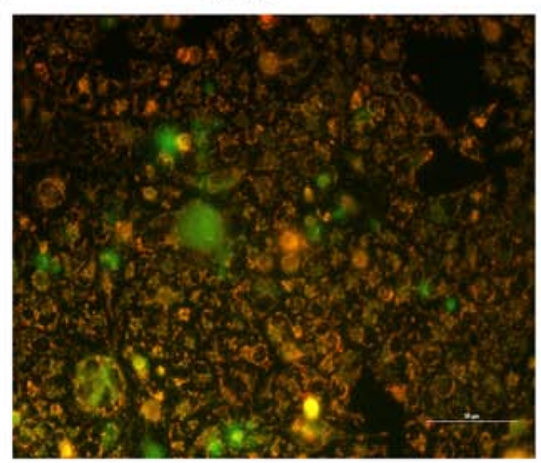

$435 \mathrm{R}+6 \mathrm{~Gy}$

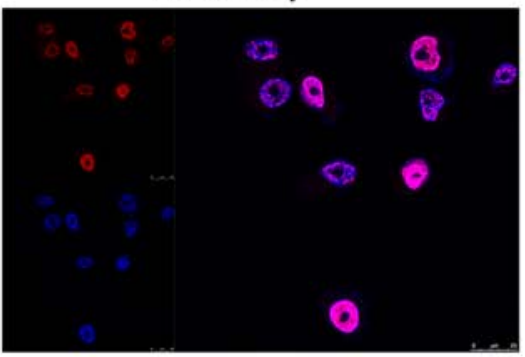

$435 \mathrm{R}+6 \mathrm{~Gy}$

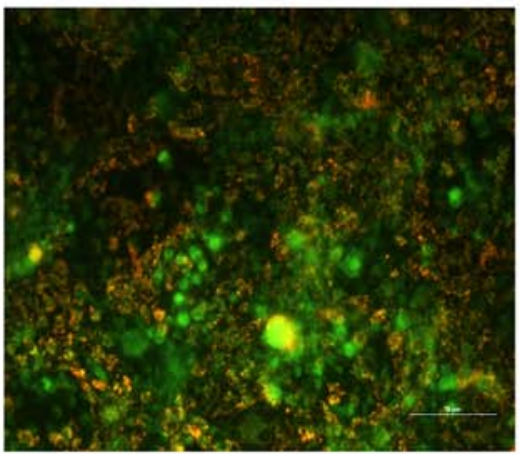

C
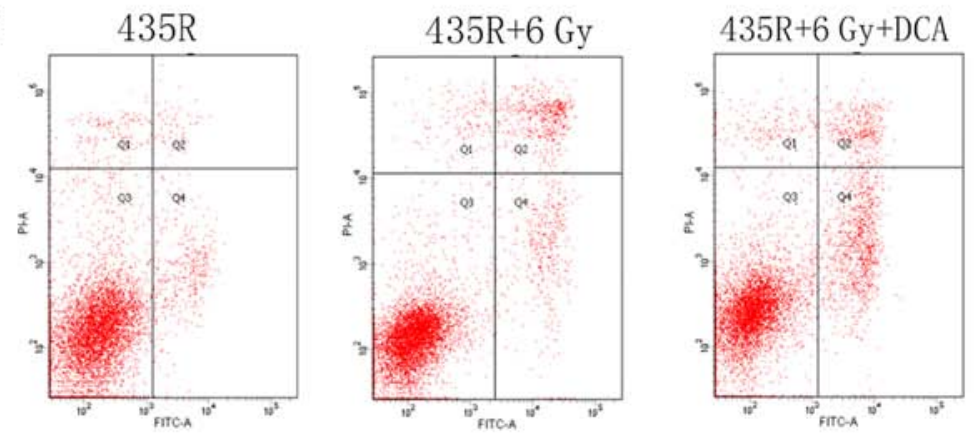
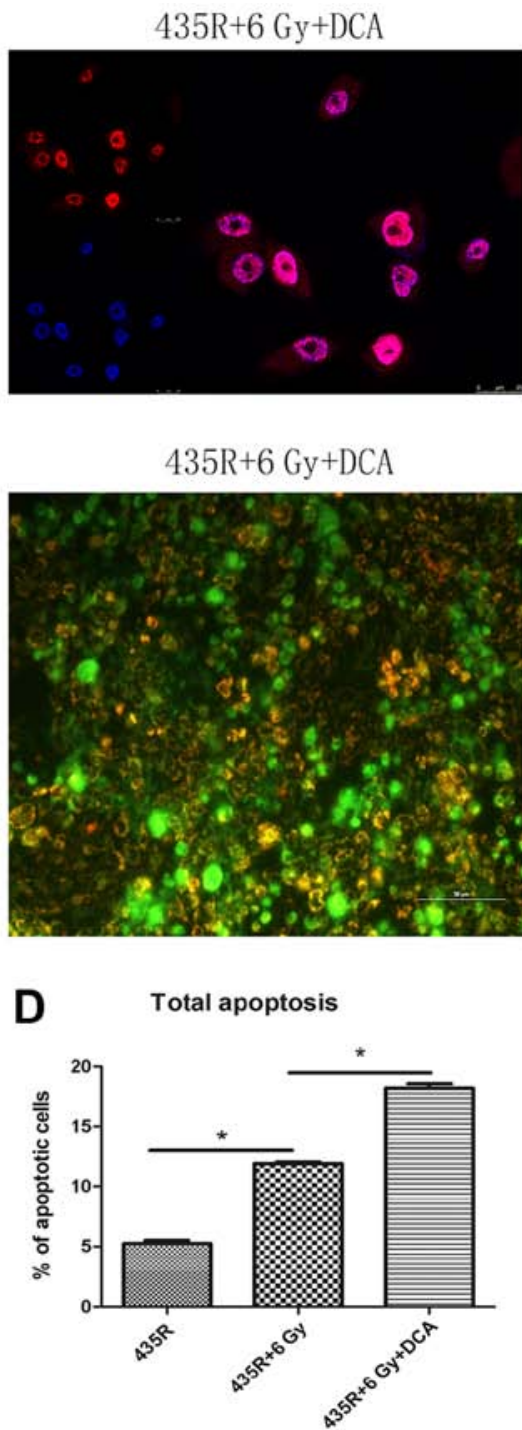

Figure 6. DCA increases DNA damage and apoptosis of 435R cells after irradiation. (A) $\gamma-\mathrm{H} 2 \mathrm{AX}$ foci in combination treatment with DCA and RT or RT alone in $435 \mathrm{R}$ cells. Upper left corner of each image is the $\gamma-\mathrm{H} 2 \mathrm{AX}$ foci with the red fluorescence in the nuclei. Lower left corner of each image is nuclei stained blue with DAPI. On the right of each image is the merged image of the left two images. (B) The change of mitochondrial membrane potential in combination treatment with DCA and RT or RT alone in 435R cells. The images demonstrate depolarization of mitochondrial membrane potential indicated by decrease of the red fluorescence combined with increase of the green fluorescence. (C) Apoptosis analyzed by flow cytometry in combination treatment with DCA and RT or RT alone in 435R cells. (D) The percentage of apoptosis on 435R cells with different treatment, ${ }^{*} \mathrm{P}<0.001$.
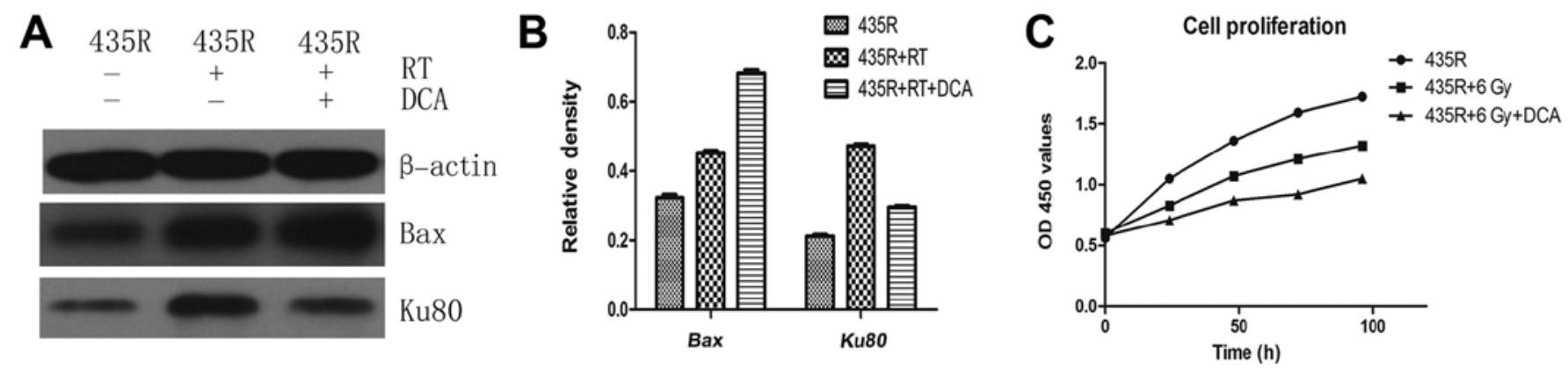

Figure 7. DCA decreases DNA damage repair and cell proliferation of 435R cells after irradiation. (A) Western blot analysis of Bax and Ku80 in $435 \mathrm{R}$ cells in combination treatment with DCA and RT or RT alone. (B) Relative density of Bax and Ku80 normalized to their internal protein. (C) Cell proliferation was detected using CCK-8 assays in 435R cells in combination treatment with DCA and RT or RT alone.

The elevated glycolytic state of cancer cells not only provides a growth advantage but also correlates strongly with radiore- sistance $(15,16)$. Therefore, inhibition of glycolytic metabolism during or before radiotherapy may be potentially exploited 
for identifying new methods to overcome radioresistance. In our study, inhibition of HIF-1 $\alpha$ caused a decrease of PDK1 expression and radioresistance in the radioresistant cells. In order to verify whether inhibition of HIF-1 $\alpha$ decreased the radioresistance of $435 \mathrm{R}$ cells via glycolysis, radioresistance of 435R cells were detected after inhibiting glycolytic state with DCA. These results demonstrated that inhibition of HIF-1 $\alpha$ sensitizes $435 \mathrm{R}$ cells to X-ray irradiation by regulating PDK1mediated glycolysis. Some special glycolysis-related enzymes which can regulate the activity of glycolysis can be the target of further investigation into combination with radiotherapy.

Radiation can induce single-strand or double-strand DNA breaks (SSBs and DSBs) by inducing the oxidation of DNA bases causing lesions in the DNA (41). As strong activators of apoptosis, DSBs have the most harmful effect on cell survival (42); cell death was induced by the persistence of DSBs if not repaired (43). Zou et al found that 2-MeOE2 could enhance the incidence of radiation-induced genomic damage (44). Ku80/XRCC5 is one of the XRCC (X-ray Repair cross-complementing) families which play a role in protecting mammalian cells from DNA damage caused by ionizing radiation and antitumor chemotherapy agents (45). Melanoma has been considered to be a highly radioresistant tumor due to its efficient DNA repair mechanism (46). Our results showed that the number of the foci of $\gamma-\mathrm{H} 2 \mathrm{AX}$ in the radioresistant cells with inhibition of HIF-1 $\alpha$ after irradiation was higher than the cells without this. The expression of Ku80 in the radioresistant cells with 2-MeOE2 was lower than the cells without after the same dose of irradiation. It demonstrated that inhibition of HIF-1 $\alpha$-mediated glycolysis could increase the DSBs and suppress the DNA damage repair of radioresistant melanoma cells after irradiation.

Inhibition of HIF-1 $\alpha$ can increase the expression of apoptosis promoting protein Bax and the apoptosis rate of $435 \mathrm{R}$ cells significantly after radiation than the cells after radiation without the inhibitor. The final results showed that inhibition of HIF- $1 \alpha$ could inhibit the cell proliferation of 435R after irradiation. Mueck et al observed that under a normoxic condition, 2-MeOE2 stimulated apoptosis, an effect probably due to Bcl-2 and Bcl-xL phosphorylation and the subsequent inhibition of the anti-apoptotic effects (47). The experiment of Long et al demonstrated that 2-MeOE2 effectively inhibited the protein expression of HIF-1 $\alpha$, which significantly increased the late stage of radiation-induced apoptosis of keloid fibroblasts (48). The results of Aquino-Gálvez et al showed a dose-dependent inhibition of cell growth for 2-ME-treated normoxic cells (49).

In summary, our study detected high expression level of HIF- $1 \alpha$ and more glycolysis activity in the radioresistant melanoma 435R cell model than its parental cells. HIF-1 $\alpha$, as a key regulator of PDK1, its inhibition can cause decrease of radioresistance and PDK1 of 435R cells. The possible mechanism of this effect might that inhibition of HIF-1 $\alpha$ supresses the glycolysis by PDK1, then the balance of energy metabolism through glycolysis is disrupted. Since Warburg effect is the major source of energy in the highly glycolytic cancers (13), imbalanced metabolism may be the critical factor that influenced biological processes, including repair of DNA breaks, cell proliferation and other processes which can change the radiosensitivity of cells. These observations have raised the possibility that targeting metabolic pathways that the cancer cell depends on may be a useful therapeutic strategy. Some special glycolysisrelated enzymes could be new targets for further investigation in combination with radiotherapy, and more cell lines are needed in the future experiments.

\section{References}

1. Slominski A, Kim TK, Brożyna AA, Janjetovic Z, Brooks DL, Schwab LP, Skobowiat C, Jóźwicki W and Seagroves TN: The role of melanogenesis in regulation of melanoma behavior: Melanogenesis leads to stimulation of HIF-1 $\alpha$ expression and HIF-dependent attendant pathways. Arch Biochem Biophys 563: 79-93, 2014.

2. Aebersold DM, Burri P, Beer KT, Laissue J, Djonov V, Greiner RH and Semenza GL: Expression of hypoxia-inducible factor-1alpha: A novel predictive and prognostic parameter in the radiotherapy of oropharyngeal cancer. Cancer Res 61: 2911$2916,2001$.

3. Koukourakis MI, Giatromanolaki A, Sivridis E, Simopoulos C, Turley H, Talks K, Gatter KC and Harris AL: Hypoxia-inducible factor (HIF1A and HIF2A), angiogenesis, and chemoradiotherapy outcome of squamous cell head-and-neck cancer. Int J Radiat Oncol Biol Phys 53: 1192-1202, 2002.

4. Mabjeesh NJ, Escuin D, LaVallee TM, Pribluda VS, Swartz GM, Johnson MS, Willard MT, Zhong H, Simons JW and Giannakakou P: 2ME2 inhibits tumor growth and angiogenesis by disrupting microtubules and dysregulating HIF. Cancer Cell 3: 363-375, 2003.

5. Maxwell PH, Pugh CW and Ratcliffe PJ: The pVHL-hIF-1 system. A key mediator of oxygen homeostasis. Adv Exp Med Biol 502: 365-376, 2001.

6. Zeng L, Zhou HY, Tang NN, Zhang WF, He GJ, Hao B, Feng YD and Zhu H: Wortmannin influences hypoxia-inducible factor-1 alpha expression and glycolysis in esophageal carcinoma cells. World J Gastroenterol 22: 4868-4880, 2016.

7. Chen Y, Cao KE, Wang S, Chen J, He B, He GU, Chen Y, Peng B and Zhou J: MicroRNA-138 suppresses proliferation, invasion and glycolysis in malignant melanoma cells by targeting HIF-1 $\alpha$. Exp Ther Med 11: 2513-2518, 2016.

8. Kim JW, Tchernyshyov I, Semenza GL and Dang CV: HIF-1mediated expression of pyruvate dehydrogenase kinase: A metabolic switch required for cellular adaptation to hypoxia. Cell Metab 3: 177-185, 2006.

9. Fujiwara S, Kawano Y, Yuki H, Okuno Y, Nosaka K, Mitsuya H and Hata H: PDK1 inhibition is a novel therapeutic target in multiple myeloma. Br J Cancer 108: 170-178, 2013.

10. Vander Heiden MG, Cantley LC and Thompson CB: Understanding the Warburg effect: The metabolic requirements of cell proliferation. Science 324: 1029-1033, 2009.

11. Koppenol WH, Bounds PL and Dang CV: Otto Warburg's contributions to current concepts of cancer metabolism. Nat Rev Cancer 11: 325-337, 2011.

12. Warburg O: On respiratory impairment in cancer cells. Science 124: 269-270, 1956.

13. Scott DA, Richardson AD, Filipp FV, Knutzen CA, Chiang GG, Ronai ZA, Osterman AL and Smith JW: Comparative metabolic flux profiling of melanoma cell lines: Beyond the Warburg effect. J Biol Chem 286: 42626-42634, 2011.

14. Bettum IJ, Gorad SS, Barkovskaya A, Pettersen S, Moestue SA, Vasiliauskaite K, Tenstad E, Øyjord T, Risa Ø, Nygaard V, et al: Metabolic reprogramming supports the invasive phenotype in malignant melanoma. Cancer Lett 366: 71-83, 2015.

15. Bhatt AN, Chauhan A, Khanna S, Rai Y, Singh S, Soni R, Kalra N and Dwarakanath BS: Transient elevation of glycolysis confers radio-resistance by facilitating DNA repair in cells. BMC Cancer 15: 335, 2015.

16. Zhong J, Rajaram N, Brizel DM, Frees AE, Ramanujam N, Batinic-Haberle I and Dewhirst MW: Radiation induces aerobic glycolysis through reactive oxygen species. Radiother Oncol 106: 390-396, 2013

17. Shimura T, Noma N, Sano Y, Ochiai Y, Oikawa T, Fukumoto M and Kunugita N: AKT-mediated enhanced aerobic glycolysis causes acquired radioresistance by human tumor cells. Radiother Oncol 112: 302-307, 2014. 
18. Yang C, Qin Y, Zhang H, Ma J and Yang K: Upregulation of SLC19A2 in stem cell-like cancer cells of nasopharyngeal carcinoma contributes to increased radioresistance through enhanced glycolysis. Int J Radiat Oncol Biol Phys 96: E582, 2016.

19. Jiang S, Wang R, Yan H, Jin L, Dou X and Chen D: MicroRNA-21 modulates radiation resistance through upregulation of hypoxiainducible factor-1 $\alpha$-promoted glycolysis in non-small cell lung cancer cells. Mol Med Rep 13: 4101-4107, 2016.

20. Liu G, Li YI and Gao X: Overexpression of microRNA-133b sensitizes non-small cell lung cancer cells to irradiation through the inhibition of glycolysis. Oncol Lett 11: 2903-2908, 2016.

21. Shen H, Hau E, Joshi S, Dilda PJ and McDonald KL: Sensitization of glioblastoma cells to irradiation by modulating the glucose metabolism. Mol Cancer Ther 14: 1794-1804, 2015.

22. Luo YM, Xia NX, Yang L, Li Z, Yang H, Yu HJ, Liu Y, Lei H, Zhou FX, Xie $\mathrm{CH}$, et al: CTC1 increases the radioresistance of human melanoma cells by inhibiting telomere shortening and apoptosis. Int J Mol Med 33: 1484-1490, 2014.

23. Franken NA, Rodermond HM, Stap J, Haveman J and van Bree C: Clonogenic assay of cells in vitro. Nat Protoc 1: 2315-2319, 2006

24. Rafehi H, Orlowski C, Georgiadis GT, Ververis K, El-Osta A and Karagiannis TC: Clonogenic assay: Adherent cells. J Vis Exp 49: 2573, 2011

25. Ning S, Shui C, Khan WB, Benson W, Lacey DL and Knox SJ Effects of keratinocyte growth factor on the proliferation and radiation survival of human squamous cell carcinoma cell lines in vitro and in vivo. Int J Radiat Oncol Biol Phys 40: 177-187, 1998.

26. Rao PN, Cessac JW, Tinley TL and Mooberry SL: Synthesis and antimitotic activity of novel 2-methoxyestradiol analogs. Steroids 67: 1079-1089, 2002.

27. Hu D and Kipps TJ: Reduction in mitochondrial membrane potential is an early event in Fas-independent CTL-mediated apoptosis. Cell Immunol 195: 43-52, 1999.

28. Jenrette JM: Malignant melanoma: The role of radiation therapy revisited. Semin Oncol 23: 759-762, 1996.

29. Stevens G and McKay MJ: Dispelling the myths surrounding radiotherapy for treatment of cutaneous melanoma. Lancet Oncol 7: 575-583, 2006

30. Rofstad EK: Radiation biology of malignant melanoma. Acta Radiol Oncol 25: 1-10, 1986.

31. Overgaard J, Overgaard M, Hansen PV and von der Maase H: Some factors of importance in the radiation treatment of malignant melanoma. Radiother Oncol 5: 183-192, 1986.

32. Masoud GN and Li W: HIF-1 $\alpha$ pathway: Role, regulation and intervention for cancer therapy. Acta Pharm Sin B 5: 378-389, 2015.

33. Pribluda VS, Gubish ER Jr, Lavallee TM, Treston A, Swartz GM and Green SJ: 2-Methoxyestradiol: An endogenous antiangiogenic and antiproliferative drug candidate. Cancer Metastasis Rev 19 $173-179,2000$

34. James J, Murry DJ, Treston AM, Storniolo AM, Sledge GW, Sidor C and Miller KD: Phase I safety, pharmacokinetic and pharmacodynamic studies of 2-methoxyestradiol alone or in combination with docetaxel in patients with locally recurrent or metastatic breast cancer. Invest New Drugs 25: 41-48, 2007.

35. Bruce JY, Eickhoff J, Pili R, Logan T, Carducci M, Arnott J, Treston A, Wilding G and Liu G: A phase II study of 2-methoxyestradiol nanocrystal colloidal dispersion alone and in combination with sunitinib malate in patients with metastatic renal cell carcinoma progressing on sunitinib malate. Invest New Drugs 30: 794-802, 2012.
36. Sweeney C, Liu G, Yiannoutsos C, Kolesar J, Horvath D, Staab MJ, Fife K, Armstrong V, Treston A, Sidor C, et al: A phase II multicenter, randomized, double-blind, safety trial assessing the pharmacokinetics, pharmacodynamics, and efficacy of oral 2-methoxyestradiol capsules in hormonerefractory prostate cancer. Clin Cancer Res 11: 6625-6633, 2005.

37. Xiao X, Huang X, Ye F, Chen B, Song C, Wen J, Zhang Z, Zheng G, Tang $\mathrm{H}$ and Xie X: The miR-34a-LDHA axis regulates glucose metabolism and tumor growth in breast cancer. Sci Rep 6: 21735,2016

38. Zhao D, Zou SW, Liu Y, Zhou X, Mo Y, Wang P, Xu YH, Dong B, Xiong Y, Lei QY, et al: Lysine-5 acetylation negatively regulates lactate dehydrogenase $\mathrm{A}$ and is decreased in pancreatic cancer. Cancer Cell 23: 464-476, 2013.

39. Shi M, Cui J, Du J, Wei D, Jia Z, Zhang J, Zhu Z, Gao Y and Xie K: A novel KLF4/LDHA signaling pathway regulates aerobic glycolysis in and progression of pancreatic cancer. Clin Cancer Res 20: 4370-4380, 2014

40. Shibuya K, Okada M, Suzuki S, Seino M, Seino S, Takeda H and Kitanaka C: Targeting the facilitative glucose transporter GLUT1 inhibits the self-renewal and tumor-initiating capacity of cancer stem cells. Oncotarget 6: 651-661, 2015.

41. Hoeijmakers JH: Genome maintenance mechanisms for preventing cancer. Nature 411: 366-374, 2001.

42. Lips J and Kaina B: DNA double-strand breaks trigger apoptosis in p53-deficient fibroblasts. Carcinogenesis 22: 579-585, 2001.

43. Fortini P, Ferretti C and Dogliotti E: The response to DNA damage during differentiation: Pathways and consequences. Mutat Res 743-744: 160-168, 2013

44. Zou H, Zhao S, Zhang J, Lv G, Zhang X, Yu H, Wang H and Wang L: Enhanced radiation-induced cytotoxic effect by 2-ME in glioma cells is mediated by induction of cell cycle arrest and DNA damage via activation of ATM pathways. Brain Res 1185: 231-238, 2007.

45. Pierce AJ, Hu P, Han M, Ellis N and Jasin M: Ku DNA endbinding protein modulates homologous repair of double-strand breaks in mammalian cells. Genes Dev 15: 3237-3242, 2001.

46. Little JB, Hahn GM, Frindel E and Tubiana M: Repair of potentially lethal radiation damage in vitro and in vivo. Radiology 106: 689-694, 1973.

47. Mueck AO and Seeger H: 2-Methoxyestradiol - biology and mechanism of action. Steroids 75: 625-631, 2010.

48. Long F, Si L, Long X, Yang B, Wang X and Zhang F: 2ME2 increase radiation-induced apoptosis of keloid fibroblasts by targeting HIF-1 $\alpha$ in vitro. Australas J Dermatol 57: e32-e38, 2016.

49. Aquino-Gálvez A, González-Ávila G, Delgado-Tello J, Castillejos-López M, Mendoza-Milla C, Zúñiga J, Checa M, Maldonado-Martínez HA, Trinidad-López A, Cisneros J, et al: Effects of 2-methoxyestradiol on apoptosis and HIF-1 $\alpha$ and HIF-2 $\alpha$ expression in lung cancer cells under normoxia and hypoxia. Oncol Rep 35: 577-583, 2016. 